CHAPTER 10

\title{
Commoning Over a Cup of Coffee: The Case of Kafeneio, a Co-op Cafe at Plato's Academy
}

\author{
Chrysostomos Galanos
}

\section{The story of Kafeneio}

Kafeneio, a co-op cafe at Plato's Academy in Athens, was founded on the $1^{\text {st }}$ of May 2010. The opening day was combined with an open, self-organised gathering that emphasised the need to reclaim open public spaces for the people. It is important to note that every turning point in the life of Kafeneio was somehow linked to a large gathering. Indeed, the very start of the initiative, in September 2009, took the form of an alternative festival which we named 'Point Defect'.

In order to understand the choice of 'Point Defect' as the name for the launch party, one need only look at the press release we made at the time:

'When we have a perfect crystal, all atoms are positioned exactly at the points they should be, for the crystal to be intact; in the molecular structure of this crystal everything seems aligned. It can be, however, that one of the atoms is not at place or missing, or another type of atom is at its place. In that case we say that the crystal has a 'point defect', a point where its structure is not perfect, a point from which the crystal could start collapsing'.

How to cite this book chapter:

Galanos, C. 2020. Commoning Over a Cup of Coffee: The Case of Kafeneio, a Co-op Cafe at Plato's Academy. In Lekakis, S. (ed.) Cultural Heritage in the Realm of the Commons: Conversations on the Case of Greece. Pp. 213-226. London: Ubiquity Press. DOI: https://doi.org/10.5334/bcj.l. License: CC-BY 
There is an obvious analogy in this statement between a crystal and social structures. The vision of our gathering was to create a small $\operatorname{crack}^{80}$ that would enable the new imagined realities to surface. Realities of equality, selforganization, creativity and mutual respect. It could be argued that in the vision of September 2009 launch party, one can find the soul of the Kafeneio, the co-op cafe at Plato's Academy.

\section{From vision to realisation}

In order, however, to properly convey the atmosphere of the Kafeneio and its evolution over time, maybe the story should start a little earlier. To begin with, it is important to clarify how we found ourselves in the area of Athens called 'Plato's Academy', especially given the fact that almost none of the members of the founding team lived there. In fact, some of us had never heard of the area that took its name from the adjacent archaeological park, on either side of the Cratylus street in the area of Kolonos, bearing the remains of the school (387 $86 \mathrm{BC})$ founded by the legendary philosopher.

Towards the end of May 2007, Kerameikos Metro station, 2.5 kilometres from Plato's Academy, opened its gates to the public. One direct effect of this was the rapid increase in business development in the wider area, especially in the domain of entertainment, food and music. As most of us lived in the affected areas, we experienced the consequences of this development and observed the distortion inflicted upon the coherence and the character of the neighbourhood. The continuous incorporation of more and more public spaces into the commercial zone was one of the main issues. Formerly abandoned corners were now cafés and restaurants and sidewalks where people used to gather and talk were now covered with tables and chairs.

Seeking to somehow act against this trend, we were lucky to find support from a very active residents' group in the neighbourhood of Plato's Academy. ${ }^{81}$ The 'Residents' Committee for Plato's Academy' created a few years earlier as a result of collective activist attempts, already had noteworthy success in blocking the construction of a multi-storey building at the edge of the park, as well as a building for the Prefecture of Athens that would have had a significant impact on the life of the neighbourhood. Our collaboration started from the 'Point Defect party' and their solidary assistance was crucial for the creation of the Kafeneio.

Although our inauguration party took place in September 2009, it was only in May 2010 that Kafeneio opened to the public. The first few months were necessary to deal with several practical issues, such as forming the founding team,

${ }^{80}$ It is perhaps interesting that at that point we completely ignored the work of John Holloway and his book Crack Capitalism (Holloway 2010).

${ }^{81}$ https://akadimia-platonos.com/. Last access 20 November 2019. 


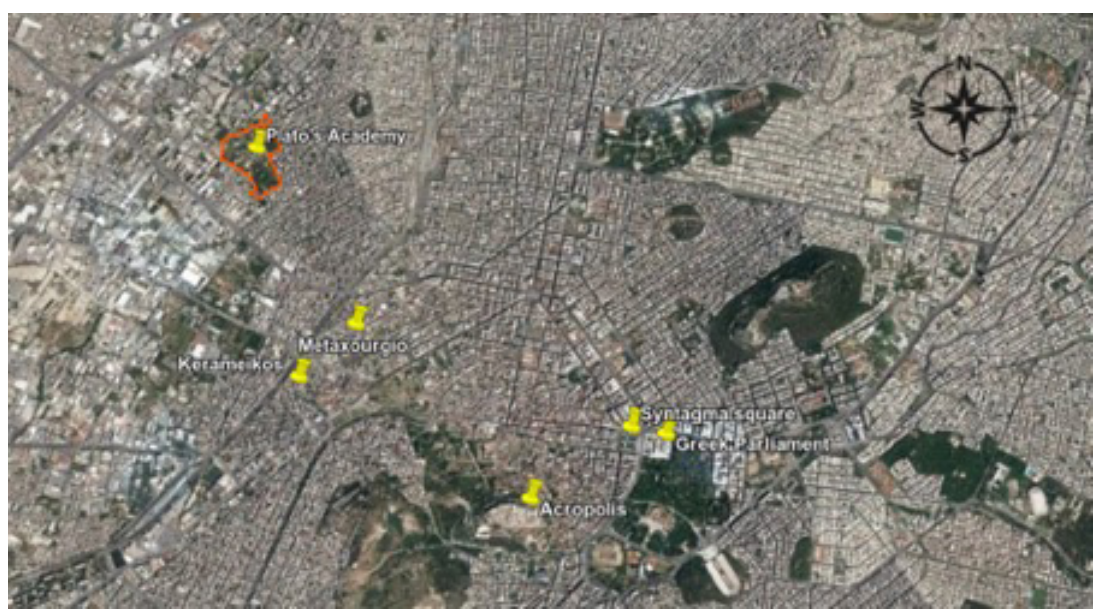

Figure 1: Panoramic view of Athens' city centre (Source: Google Earth).

deciding the goals of the initiative, choosing the right legal form, sorting out financial issues, dealing with interpersonal problems and much more.

From the beginning, we aimed to network with other initiatives in the field of the Social and Solidarity Economy that either already existed or were also starting at the time. Back in 2010 we were pioneers, as the only known initiative to exist before us was 'Sporos' ${ }^{\text {'2 }}$ in Exarcheia, while about a month after the founding of Kafeneio, a workers' collective named 'Pagkaki' was founded in the area of Koukaki in Athens. It is interesting to note that within a few months dozens of formal or informal groups had come to life, trying to respond to the obvious contradictions and malfunctions of the dominant economic model and to experiment with new types of social organisation.

A defining factor for the extension and growth of similar ideas and initiatives was without doubt the 'Aganaktisménoi' (Indignants) movement and the square protests that spread throughout Greece in May 2011. The most important of these were the demonstrations at Syntagma square in Athens (Papapavlou 2015). One might think that including these facts in the narrative here might be irrelevant to the story of Kafeneio, however, these historic moments helped us define and update our role and our relationship to the prevalent social issues of the day. This period was very important, since it was the first time that relatively newly appearing notions and practices, such as common goods, eco-communities, time banks, alternative currencies and Social \& Solidarity Economy (SSE), were experientially introduced into the everyday vocabulary of the people participating in collective processes. In my view, these terms helped people obtain a common vocabulary for things they were already doing but were uncertain of how to express or communicate them.

${ }^{82}$ Seized operation in Autumn 2012. 
This transformational language of the commons helped us to escape the bipolar view between the market and the state and the hidden pitfalls in the ways in which we defined problems and located solutions (Bollier \& Helfrich 2012). From the moment, a third dimension, this of the commons, was introduced to the system dominated from the market and the state and a new horizon opened up regarding action and thought towards the co-creation of a different world.

This was a period in which we also discovered the vocabulary to articulate the fact that the main drive that propelled us to take action next to the archaeological park was the need to protect the park itself and highlight its value as a common good.

A further, very important event for the development of relations between the emerging alternative initiatives, as well as for the adoption of a commons vocabulary was the Alternative Festival of Solidarity and Cooperative Economy (fest4sce), which took place for the first time in the Ellinikon Cultural Center in October 2012. The festival aimed to become a central event in facilitating local and international initiatives to introduce themselves to each other and to network. The event was subsequently repeated annually for four years, with the last two, in 2015 and 2016, taking place in Plato's Academy. The high levels of interaction and osmosis among the actors of the emerging world of the commons and the success of the events were applauded. As a result, in October 2017 the festival was incorporated into the Festival of the Commons ${ }^{83}$ in Athens. Kafeneio, both as a project and through its members, was present from the first moment in these five years, participating in the Festival's organising committee. It is also worth mentioning that the first ever presentation made in the Festival was about Kafeneio in Plato's Academy.

Thus, since 2012 an active community of social, cooperative and solidarity economy and of the commons has emerged, with a clear vision of a social transformation rather than merely dealing with the neoliberal financial crisis. As a part of this community, our goal was to make Kafeneio a welcoming space, where groups and individuals could meet, exchange opinions and present their ideas; a hub of collaborative energy, information and knowledge in the developing horizontal ecosystem of an emerging new world.

\section{Issues within the team and how we dealt with them}

Every initiative has its difficulties, even more so when many individuals, business activity, financial problems and unprecedented bureaucratic issues are involved. In fact, the combination of all the above created an unstable situation for the management of the initiative. In our case, we had to go through various difficult paths and many times we almost abandoned the project. However, in

${ }^{83}$ https://commons.gr/festival/. Last access 20 November 2019. 
spite of all of this, we are still there, offering Zapatista coffee to anybody who wants to enjoy it.

A major difficulty that we had to deal with, from the very beginning, was to choose the right legal form. We were very conscious about what we wanted to do as an informal group, but when it came to be settling into a specific legal form, there was a gap in the law. We wanted to create an initiative that would function as a part of the social, cooperative, non-profit economy. Back in 2010 there was no specific law for SSEs, such as exists today (L.4019/2011 amended by L.4430/2016), that provided directions to the local authorities on how to deal with projects like ours. In our case, we came to the conclusion that the legal form closest to our aspirations was the non-profit civil company. After long discussions and clarifications with the local authorities that almost made us give up the project before it even started, we eventually managed to be granted an operating license as 'European Village', a pre-existing, civil, non-profit company, aligning in vision and objectives with the idea of the Coop Café.

Even more central and harder to deal with are the interpersonal issues that arise among the members of a team and are related to topics such as the decision making processes, the conscious or unconscious power games, conflict management, the definitions of goals and the balance between financial viability, efficiency and self-management. This is a long list of crucial issues about which we learned nothing in school or university, since the dominant system does not teach us how to collaborate but how to function as individuals within a hierarchy. Soon we realised that good intentions are usually not enough, because the way we are brought up has created automatic reactions that prevail against well-meaning ideals.

\section{Tools that helped us}

It is very important to know that it is not necessary to reinvent the wheel over and over again and it is relieving to find out that your unpleasant experiences have most likely already been dealt with by others. There are people out there who have already carried out many experiments and are in a position to suggest solutions ${ }^{84}$ for anybody who wants to take them and adapt them to their needs. If this sounds like commons-based peer production of solutions for collective issues, it really works like this!

An issue that required a long time to understand was the fact that an assembly is not just a gathering where each participant shares their opinion, especially when there is an agreement for the decisions to be taken with consensus. Any tool can become a disadvantage when used improperly, thus the assembly, the soul of any cooperative initiative, can easily become a synonym for time wasting. One thing that helped us a lot was the creation of supporting roles for

${ }^{84}$ For example, http://www.circleway.org/. Last access 20 November 2019. 
the assembly. A facilitator and a rapporteur are the minimum required set of roles. Indeed, specific roles such as that of the facilitator's are admittedly quite demanding and for this reason it was necessary for quite a few members to get the relevant training.

The circle is also a very important part of the process, since it facilitates the equal participation and creation of a safe environment. In practice, we realised that even if we focused overly on specific decision-making processes, there were often emotional blockages that prevented us from reaching solutions. In order to avoid this, we decided to include a monthly meeting in our shared practices, which we named 'assembly of emotions', aimed at dealing exclusively with personal issues. While we only followed this practice for a short while, it produced clear results and we would argue that it has significant potential. Although also in this case it must be said that the presence of at least one experienced facilitator is crucial.

Another important practice that helped us crucially is the tool of Nonviolent Communication (NVC). NVC is a process that helped us realise, locate and deal with the violence we receive and give to others and ourselves every day (Nonviolent Communication 2018). We were lucky enough to host some of the first NVC workshops in Greece, which of course had an influence on the members of our group. In fact, the first NVC certified trainer in Greece is a member of our group.

Mediation is also a practice that gave us positive results whenever we used it. A mediator is a trained person who holds a neutral position and their job is to help two conflicting parties to understand each other's needs and thus find new, mutually acceptable solutions (Mediation 2018). Some of our members were also trained to be able to play the role of mediator.

However, there were moments when we realised that we had to ask for external help, since the team by itself did not have the knowhow or the emotional strength to deal with certain issues. In one of those cases we asked for the help of 'Metaplasis', a non-profit informal group which organised structured dialogue and communication processes (Metaplasis 2018). The process lasted for almost three months. It started with one on one interviews with all of the members carried out by the representatives of 'Metaplasis' and proceeded to meetings with the whole team. It really helped us to deal with the communication crisis we were undergoing, and it also stressed the importance of facing up to issues instead of trying to hide them.

What is more, on two occasions we organised Strategic Planning gatherings: in April 2015 and November 2017. The members of our organisation met and spent 3 days discussing our issues, thoughts, feelings and desires. This was followed by a stage in which we redefined our vision and goals. Living together for a few days outside Athens under the same roof helped us substantially to get over certain situations and move on. These meetings combined communal living with a specific set of activities and practices. Some of the tools we 
used were Open Space Technology, Mind Maps, Collective Story Harvesting, S.W.O.T analysis, graphic facilitation and many more. In our 2015 gathering, we had support from external facilitators, ${ }^{85}$ while in the 2017 event we used our acquired skills and knowledge to manage the processes ourselves.

Finally, since 'European Village' takes part in European Mobility Programs, its members and affiliated participants have often had the opportunity to travel throughout Europe, to acquire new experiences in non-typical, experiential education and to become familiar with initiatives outside Greece. One of the most notable cases was our participation in the program 'Hétérotopies, ${ }^{86}$ which was inspired by the ideas of the philosopher Michel Foucault and aims to discover alternative existent worlds where things are different from the mainstream. It is through becoming aware of the existence of all of these different spaces that we have kept on working for social transformation and for the transformation of our everyday life.

\section{Developing urban commons}

As mentioned previously, many of the activities that were carried out in the first period were the result of the needs that existed among the members of the group, who did not always have the vocabulary to express them and communicate them properly. For example, it has been stated that it was necessary to ensure our presence next to the archaeological park as a point of resistance to possible future commercialisation efforts in the area with the consequence of altering the character of the neighbourhood. It also felt important to preserve a point in the city that allows citizens to have contact with the natural environment.

Over time, we realised that what we were promoting through our activities, in relation to the park, was the development of the urban commons. Our first contact with the area was through a celebration that was primarily aimed at socialising, reclaiming the public space and the self-management of our entertainment. These key features have remained central to the events we have held or helped to take place in the area since. In the words of one inhabitant of the area "you broke the neighbourhood taboo of organising activities in the park" (Resident 2010, pers com.), a sentiment that gave us great strength in continuing our activities.

The root of our actions is always linked to the following question: 'If a neighbourhood is not accustomed to using its space, then who is going to claim it, if private interests attempt to appropriate it?'

Indicative examples of the conscious development of the idea for Plato's Academy as an urban commons are the following activities:

${ }^{85}$ http://www.aoh-athens.gr/. Last access 20 November 2019.

${ }^{86} \mathrm{http}: / /$ www.viabrachy.org/h\%C3\%A9t\%C3\%A9rotopies/le-projet. Last access 20 November 2019. 
- a discussion organized, on the initiative of Kafeneio members, at the $3^{\text {rd }}$ Alternative Festival of Solidarity and Cooperative Economy, titled: 'Plato's Academy collectives: Transforming public space to common space while building human relationships. The case of the Plato's Academy's archaeological park'.

- a discussion at Commons Fest 2015 in Athens by 'Koino Athens' team, titled 'Urban Commons Practices', where one of the three examples discussed was the case of the Plato's Academy Park (Theodorou 2015).

- an open discussion / participatory design workshop, titled 'Common Goods - Common Objectives: The Plato's Academy Park as a Common Good and the struggle against the construction of the Mall' that took place at Kafeneio at $21^{\text {st }}$ November 2017 in co-organization with the team Urban Transcripts Unit 4 (European Village 2018a).

- in the framework of the $4^{\text {th }}$ meeting 'Dialogues in Archaeology' held in Athens, May - June 2018, Plato's Academy hosted many activities in the neigh-

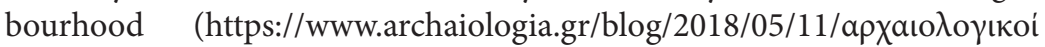

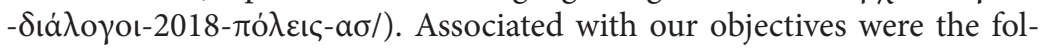
lowing two:

- A 'Silent Walk at Plato's Academy', co-organised by the Plato's Academy participatory design team. The Silent Walk was completed with an open discussion with residents of the area, debating on the significance of the Park as a cultural heritage asset and a common good for the city.

- 'The Museum as a common good' workshop by SOMA team (Scattered Open Museum of Attica), aimed at contributing to the wider effort of the residents to 'see' the park of the Plato's Academy as common good. In the workshop, appropriate museological practices were discussed, highlighting the cultural identity of the Park and the dynamics of the area as its central and symbolic core (Nonplan 2018).

Events with a similar aim are the many self-organized, community festivals that have taken place at Plato's Academy in recent years. ${ }^{87}$ It is important to put an emphasis on some of the events that took place in the park of Plato's Academy, which were of particular importance. The first was the two-day event organized by collectives of the neighbourhood on March 30-31, 2013. The central slogan of the event was 'We defend the Commons, we are creating communities of active solidarity' (European Village 2018b). The other two were the $4^{\text {th }}$ and the $5^{\text {th }}$ 'Alternative festivals of Solidarity and Cooperative Economy' that took place on October $16^{\text {th }}-18^{\text {th }} 2015$ and June $3^{\text {rd }}-5^{\text {th }} 2016$, with the central slogan 'Come to our Autonomous village'.

There are two reasons to focus specifically on these two events: Firstly, because they were large-scale events, with thousands of visitors; secondly because they

${ }^{87}$ For a very good example check: https://www.youtube.com/watch?time _continue $=108 \& v=8$ pKy3PZCAUQ. Last access 20 November 2019. 


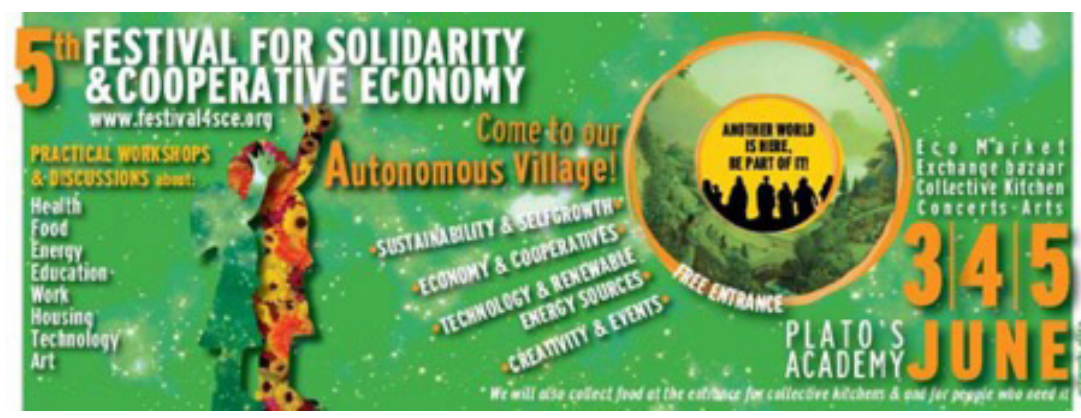

Figure 2: $5^{\text {th }}$ fest4sce at Plato's Academy: "Come to our Autonomous Village" (Source: author).

were powerful events that allowed the space to acquire the character of an urban commons. These events were created through assemblies of collectives that, if only for a few days, took over total responsibility for the space. By creating these Temporary Autonomous Zones, we succeeded in projecting ourselves into non-hierarchical systems of social relations (Temporary Autonomous Zone 2018).

\section{Who really manages cultural heritage?}

The great difference between this park and other green areas is its significant cultural heritage. We must not forget that we are dealing with an archaeological site of global importance. One need only point to the fact that Plato's 'Republic' is the most widely cited in Universities curricula (Ingraham 2016) whereas the word 'Academy' derives its origin from this place.

A central question is 'who is the most competent body to manage this cultural heritage'? Or to put the question differently 'who are the stakeholders whose opinion should be taken into account?'. In many cases the Greek state has shown that the citizens and their opinion do not have any validity in its plans. A prominent example of this was the construction of a small museum at the edge of the park. Most residents expressed a positive opinion about the construction of the museum, but were opposed to the choice of the site, putting forward reasonable arguments. They went as far as to propose an alternative spot in the immediate vicinity with many comparative advantages. However, in the end, the museum was erected in an area that everyone knows is inappropriate, and the neighbourhood lost valuable green space as a result. ${ }^{88}$ Thus, a situation that could easily be mutually beneficial, ultimately becomes problematic simply because it does not take into account the suggestions of those who are most involved; the residents of the area.

${ }^{88}$ http://www.plato-academy.gr/museum. Last access 20 November 2019. 


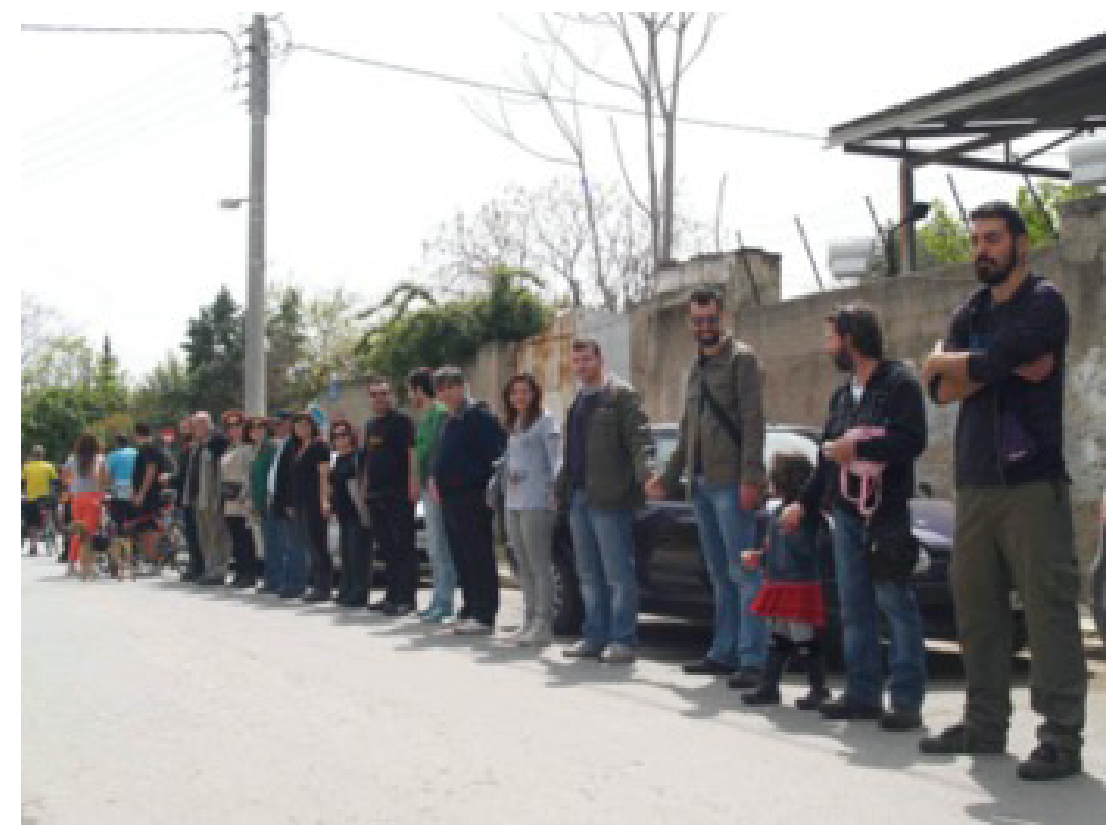

Figure 3: Defending the park (Source: author).

The question is, how much democracy is involved in a state mechanism that constantly treats citizens as immature agents and displays a paternalistic manner of dealing with problems? Furthermore, when local communities are excluded, can a heritage resource remain alive and an asset for future generations or does it become void of meaning? Our experience tells us that ordinary people spontaneously and rapidly demonstrate most of the necessary skills for collaboration, problem solving and shared responsibility. Provided that appropriate tools for identifying and recording collective intelligence exist, there can be a lot of positive surprises.

From our experience in the perimeter of the Park, a number of relevant successful examples can be discussed, ranging from symbolic human chains to defend the Park against any kind of private interests but also activist and free Park tours for visitors and public engagement events for the wider public; the fire jumping event on St. John's 'Klidonas' name day, admittedly remains the most successful engagement scheme.

\section{The looming threat has a name: Academy Gardens Mall}

As Harvey (2013: 78) insightfully discusses, there is a palpable threat for those who create a stimulating everyday neighbourhood life, as they can easily loose it to the predatory practices of the "real estate entrepreneurs, the financiers and 


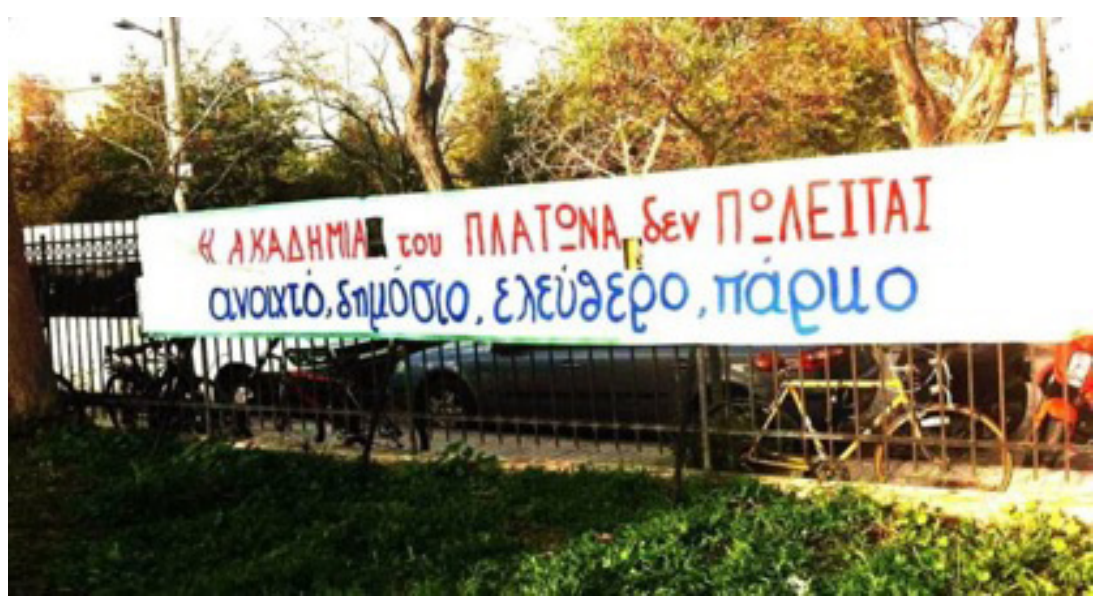

Figure 4: Plato's Academy is not for sale: Open, public, free park (Source: author).

upper-class consumers bereft of any urban social imagination". And this threat of appropriation by private profit-maximizing interests is more imminent the better the common qualities a social group creates.

The most difficult battle the local actors and citizens of Plato's Academy have been taking part in over the last few years is against the plans of the omnipotent multinational BlackRock, which - through its subsidiary Artume - aims to construct a massive, 55.000 square meter mall in the area. This effort to appropriate the huge cultural heritage of the area is shamelessly highlighted by its very name, 'Academy Gardens Mall'. 89

Despite the fact that before coming to power the previous governing political party (SYRIZA) passionately opposed the construction of the mall, the previous Environment Minister gave the green light to the project by signing the required licenses (GTP editing team 2018), reiterating the promise of development and job creation; this is an empty narrative fabricated to lure people, living in job uncertainty or socially precarious conditions.

The residents and the actors of the area know very well that the only thing they can use against the ways of the private capital and the state is agility and solidarity. The 'Open Co-ordination Committee Against the Mall' has already taken action to highlight the looming threats; There is no doubt that the construction of the Mall will have serious and non-reversible impact on the natural environment of the area. A recent economic study, concluded that the Mall will also result in the loss of 6.000 jobs in the local markets, thus dealing a fatal blow to the local economy. What is more, side to imminent issues rising as the traffic pressure for the wider area, more detriment effects as those on the social

${ }^{89}$ More info and an international petition against the mall here: http://academy gardens.org/. Last access 20 November 2019. 
fabric of the area are still unaccounted for. Lastly, but most disturbingly, is the fact that a multinational company is trying to appropriate a place of universal cultural value to make private profits (Plato's Academy blog 2018).

The citizens have submitted a series of concerns and proposals to the authorities without receiving an adequate answer. What they are focussing on is a mindful development strategy based on the local and regional needs, respecting the culture, the resources and the residents of the area (Plato's Academy blog 2018). This could be the overarching goal leading the upgrade of the neighbourhood and the enhancement of the archaeological site, open and accessible as a common good; extending the 'Unification of the Archaeological Sites of Athens' project to include the area in question and the development of a 'Museum of the City of Athens' could be important milestones in the process (Garidi 2018).

\section{Within all this, where do we stand?}

Kafeneio is still open to the public at the corner of the Park. We still view our initiative as an urban experiment of social transformation. With our stance, with the sharing of our space, with the tools we have developed and in any other way we can, we are trying to support actions that lead us away from the monoculture of the dual logic 'Market or State'. There are many alternatives, there are various heterotopies. We can create temporary autonomous zones and breathe clean air. Our motto 'building human relationships' says it all: Our

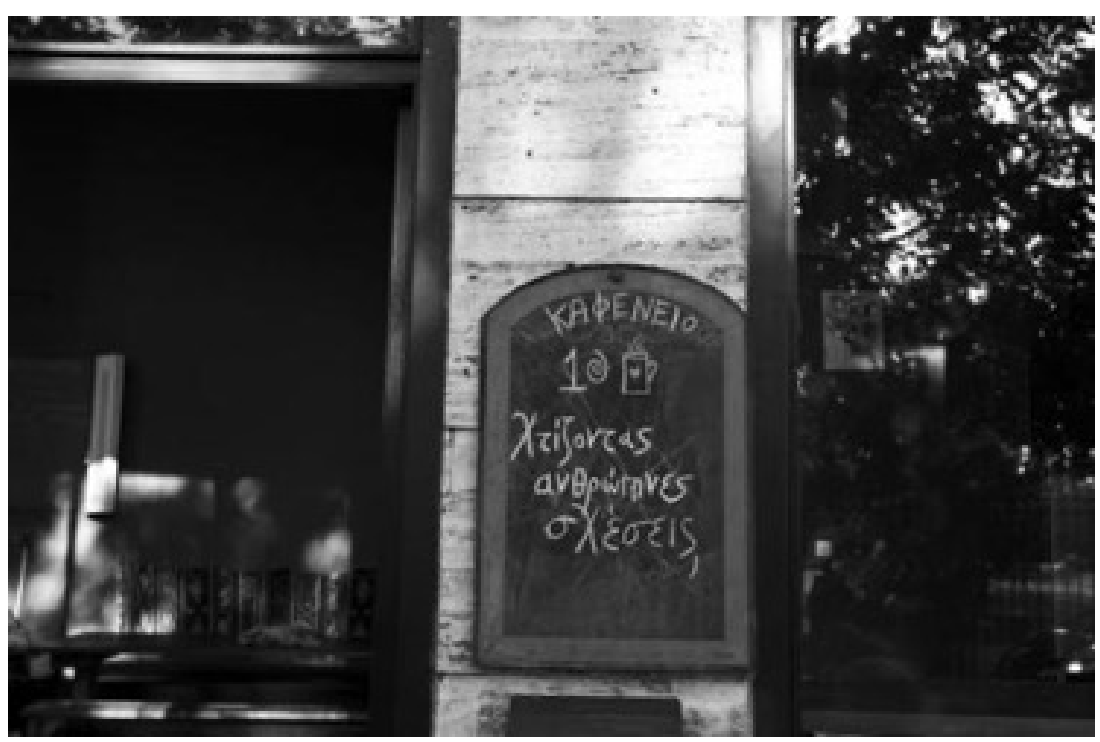

Figure 5: "Building human relationships", outside of the co-op Café (Source: author). 
hope is that we are doing our part in the process of commoning and in the protection of the Park as a common good.

\section{Acknowledgements}

The author wishes to thank the "family" of Kafeneio for co-creating this amazing journey and especially Katerina Troullaki and Giorgos Tsitsirigkos for their support in the translation of the text.

\section{Bibliography}

Bollier, D. \& Helfrich, S. (Eds.). (2012). The wealth of the commons: A world beyond market and state. Amherst, MA: Levellers Press.

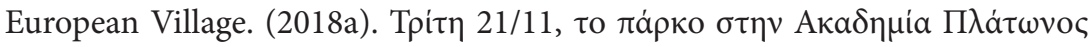

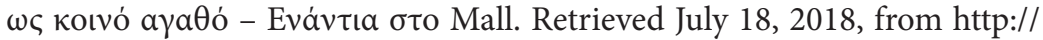
www.european-village.org/eventsview.asp?id_newsdata=3466\&ekdosi=eve nts\&katigoria=dromena_sto_kafeneio.

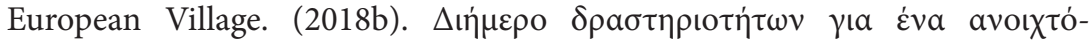

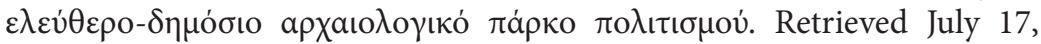
2018, from http://www.european-village.org/eventsview.asp?id_newsdata $=195 \&$ ekdosi=events\&katigoria=sinvainoun_kai_mas_aresou.

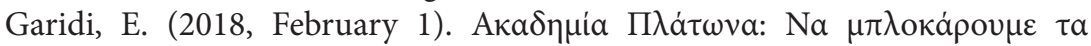

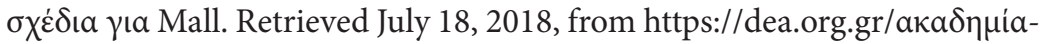

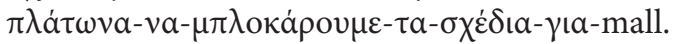

GTP editing team. (2018, January 11). Athens' Academy Gardens Mall gets green light. Gtp-Greek Travel Pages Headlines. Retrieved July 17, 2018, from http://news.gtp.gr/2018/01/11/athens-academy-gardens-mall-gets-green -light/.

Harvey, D. (2012). Rebel cities: From the right to the city to the urban revolution. London, United Kingdom: Verso.

Holloway, J. (2010). Crack Capitalism. London, United Kingdom: Pluto Press.

Ingraham, C. (2016, February 3). What Ivy League students are reading that you aren't. The Washington Post. Retrieved July 17, 2018, from https:// www.washingtonpost.com/news/wonk/wp/2016/02/03/what-ivy-league -students-are-reading-that-you-arent/.

Mediation. (2018). Retrieved July 17, 2018, from Wikipedia: https://en .wikipedia.org/w/index.php?title $=$ Mediation\&oldid $=845420140$.

Metaplasi. (2018). Metaplasi. Retrieved July 17, 2018, from http://metaplasis .org.

Nonplan. (2018, June 10). Museum as Commons @ Academy of Plato (II). Retrieved October 12, 2018, from http://soma.nonplan.gr/2018/06 /museum-as-commonsacademy-of-plato-ii/. 
Nonviolent Communication. (2018). Retrieved July 17, 2018, from Wikipedia: https://en.wikipedia.org/w/index.php?title=Nonviolent_Communication \&oldid $=848528006$.

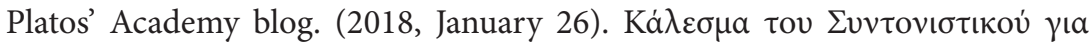

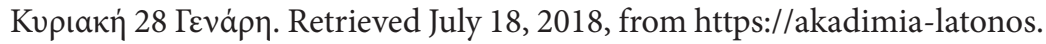

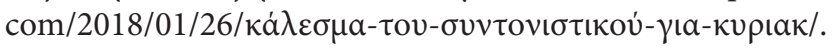

Temporary Autonomous Zone. (2018). Retrieved July 17, 2018, from Wikipedia: https://en.wikipedia.org/w/index.php?title=Temporary_Autonomous _Zone\&oldid=849740148.

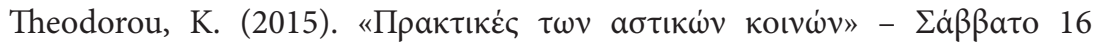

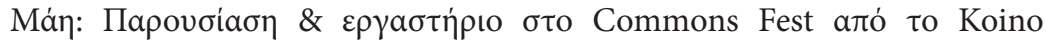
Athina. Retrieved July 17, 2018, from https://koinoathina.wordpress.

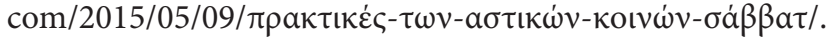

